\title{
THE EFFECTS OF GROUP VERSUS SINGLE HOUSING ON HOME CAGE BEHAVIOUR IN TWO STRAINS OF LABORATORY MICE
}

\author{
Ahmed F. Abou-Elnaga1, Ibrahim F. Rehan ${ }^{2 *}$, Ralph RJ. Thompson ${ }^{3}$, Usama A. Abou-Ismail ${ }^{1}$, \\ Motamed E. Mahmoud ${ }^{4}$, Radi A. Mohamed ${ }^{5}$, Hesham H. Mohammed ${ }^{6}$, Ahmed A. Sabek ${ }^{7}$, \\ Mohamed Z. Elhussiny ${ }^{8}$.
}

${ }^{1}$ Department of Husbandry and Development of Animal Wealth, Faculty of Veterinary Medicine, Mansoura University, P.O. Box 35516, Egypt, ${ }^{2}$ Department of Animal Behaviour and Husbandry (management, genetics and breeding), Faculty of Veterinary Medicine, South Valley University, 83523, Egypt, '3niversity of Edinburgh, UK, ${ }^{4}$ Department of Animal Behaviour and Husbandry (management, genetics and breeding), Faculty of Veterinary Medicine, Sohag University, 82524, Egypt, ${ }^{5}$ Department of Aquaculture (Animal and Fish Behaviour and Welfare), Faculty of Aquatic Sciences and Fisheries, University of Kafrelsheikh, P.O. Box 33511, Egypt, ' ${ }^{6}$ Department of Veterinary Public Health, Faculty of Veterinary Medicine, Zagazig University, 44511, Egypt, ${ }^{7}$ Department of Veterinary Hygiene and Management, Faculty of Veterinary Medicine, Benha University, 13736, Egypt, ${ }^{8}$ Department of Animal \& Poultry Behaviour and Management, Faculty of Veterinary Medicine, Aswan University, 81528, Egypt

${ }^{*}$ Corresponding author, E-mail: ibrahim.rehan@vet.svu.edu.eg

\begin{abstract}
Studying the behavioural patterns of animals in their house may help to understand their needs, but there has been a little investigation of home-cage behaviours in commonly used inbred strains of mice such as C57BL/6 and DBA/2. Therefore, understanding behavioural patterns in these mice is important for neuroscience research. For the first time, this experiment was carried out to investigate the long-term effects of housing conditions (single vs. group) on home cage behaviour of C57BL/6 and DBA/2 mice, in order to reveal differences between C57BL/6 and DBA/2 in home-cage behaviours and in response to single-housing. Sixty-four mice (32 mice/strain) were housed either singly $(\mathrm{SH})(\mathrm{n}=32)$ or in four groups, each group contained 8 animals. Home cage behavioural patterns were recorded weekly using ethogram-based instantaneous sampling for 5 consecutive weeks. Regardless of strain, single housed (SH) mice displayed higher levels of grooming and bedding directed-behaviours and were more frequently seen in-the-crawl ball, and had lower levels of feeding behaviour compared to their group housed $(\mathrm{GH})$ conspecifics. There were significant strain differences in anxiety-related behaviours with the DBA/2 strain demonstrating higher levels of sleep, feeding and grooming behaviour and frequent presence in-the-crawl ball, and lower levels of exploration, locomotion and bedding-directed behaviour compared to the C57BL/6 strain. The results therefore suggest that different housing systems influence home cage behaviours of laboratory mice with the mice of the DBA/2 strain appearing more anxious. These findings may also have great implications for researchers to decide the most appropriate phenotype to use in measuring neural response-relevant behaviours in novel animal/human models.
\end{abstract}

Key words: anxiety; behaviour; C57BL/6; DBA/2; ethogram; home-cage 


\section{Introduction}

The housing conditions of laboratory rodents have been demonstrated to induce changes in their behaviour, physiology and pathology (1) which in turn could impact the reproducibility and validity of experimental results. An important aspect of the housing conditions is the social environment (e.g. single versus group housing). Improving the housing conditions of laboratory rodents may enhance welfare in these animals by promoting their ability to cope with the environment, and may also improve the accuracy of experimental data by providing a more valid animal model for research, and may therefore reduce the number of animals used.

The hypothesis that alterations in home-cage behaviour can upset neural circuit function has attracted much consideration of the recent years both in the context of disease detection and more commonly to quantify food consumption and activity parameters (2). Moreover, great effort was directed towards the 'mouse phenome' relating characterization of common inbred strains to various behavioural tests (3). Significant differences have been found between inbred mice strains in spontaneously emitted activity, particularly in the open-field test (4). In addition, large genetic differences in movement as a response to stimulant administration (5) could provide evidence of genetic associates with many behaviours, such as sleep (6). Studies carried out on inbred strains of mice have revealed consistent differences in behaviour due to the biological functions of their genotype (7). In addition, many different inbred genetic lines showed differences in behaviour which pose challenges when seeking functional explanations for specific neural mechanisms (8). Therefore, there is interest in assigning particular behavioural phenotypes as characteristic features to easily differentiate each mouse strain and further to develop easy criteria to assess their behavioural competences (9).

C57BL/6 and DBA/2 are two of the commonly used inbred strains of laboratory mice. Numerous behavioural differences have been reported between them (10); furthermore, envi- ronmental manipulations have induced remarkable differences in epigenetic effects between strains (11). Studying home-cage behavioural differences between strains can yield several advantages for behavioural phenotypic purposes e.g. reliable measurement of stable behavioural circadian rhythms that are highly responsive to environmental signals, such as light and human interference (12).

Individual housing is generally not recommended for social laboratory rodents such as mice as it compromises their welfare, but there remains some confusion surrounding the impact of individual housing on mice. Many authors illustrated that single housing, compared to group housing of mice does not amplify urinary corticosterone level (13-16), whereas others agreed that individual housing for social animals like mice is a stressful condition (17). Measures of physiological stress; however, do not necessarily correlate with subjective welfare of the animal. Together with the conflicting research on stress this highlights the need for a further investigation onto the impact of individual housing on mice, and how this might differ between strains, especially on the consequences for their behaviour. In the present study, the home-cage behaviour of single and group housed C57BL/6 and DBA/2 mice was investigated using ethogram-based behavioural observation.

\section{Material and methods}

\section{General animal housing}

Sixty-four adult male mice (32 C57BL/6J and $32 \mathrm{DBA} / 2$ ), purchased from the Animal House, Theodor Bilharz Research Institute, Giza, Egypt, were used in this experiment. The mice were 10 weeks of age on arrival and had an average body weight about $28 \mathrm{~g}$. After transportation, all animals were given 2 weeks to habituate to their new environment and to adjust to the new lighting regime and were therefore 12 weeks of age at the start of the experiment. All cages were supplied with sawdust (as bedding material) and a crawl-ball $(115 \mathrm{~mm}$, with $3 \times 58 \mathrm{~mm}$ holes, polycarbonate ball, Lillico, UK) as an enrichment object. Cages were inspected daily and were cleaned once a week, 
during which mice were removed and rehoused in clean cages with new bedding material. Mice had ad-libitum access to pelleted food

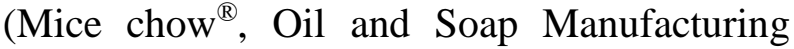
Company, El-Gharbia, Egypt) and tap water, were maintained under conditions of controlled temperature $\left(22 \pm 2{ }^{\circ} \mathrm{C}\right)$ and humidity $(60 \%)$ and were checked daily. The room was maintained under a 12:12 h light/dark cycle. Lights were turned off at 19:00 $\mathrm{h}$ and on at 07:00 $\mathrm{h}$ with a continuous dim red light allowing observation in the dark phase.

The group housed mice were marked on their tails by using a permanent marker pen to allow individual identification and these marks were refreshed every week throughout the experimental period. Likewise, the single housed mice were handled every week to avoid the behavioural changes between the two groups.

All experimental procedures were performed in accordance with the agreement for the Animal Care and Use and Approval of Ethics Committee for Animal Experimentation of Mansoura University, Egypt and care was taken to comply with the $3 \mathrm{R}$ concept.

\section{Experimental treatments}

A total of 64 mice representing two strains (32 mice of DBA/2J strain and 32 mice of C57BL/6J strain) were arbitrarily assigned to one of the following two experimental treatments:

1) "Single housing" (SH): 16 mice of DBA/2J strain and 16 mice of C57BL/6J strain $(\mathrm{n}=32)$ were housed singly in Plexiglas cages $(27.5 \mathrm{~cm}$ length $\times 16.5 \mathrm{~cm}$ width $\times 21.5 \mathrm{~cm}$ height).

2) "Group housing" (GH): 16 mice of DBA/2J strain and 16 mice of C57BL/6J strain $(n=8)$ were housed in groups of four in Plexiglas cages $(27.5 \mathrm{~cm}$ length $\times 16.5 \mathrm{~cm}$ width $\times$ $21.5 \mathrm{~cm}$ height).

All animals were introduced to their particular experimental treatments at 12 weeks of age and were naïve to the housing conditions. They were kept under the same housing condition until they were 17 weeks old; the age at which data collection was stopped.

\section{Behavioural assessment}

In order to allow mice to habituate to the presence of the observer, the observer entered the experimental room 10 min before the observation started (18). Behaviour of the mice in each cage was recorded in the usual housing location during the dark phase when mice are most active. Observations were made in real time using an instantaneous scan sampling method with 10s intervals. Each sample interval was prompted by an audio cue via headphones, and the behaviour was recorded into a check sheet. Observation sessions, were carried out consecutively on the same day, and lasted 640 s (100s per mouse, yielding 10 scans per mouse for each of 64 mice). Observation was carried out for each cage once per week for five consecutive weeks. This meant a total of 50 scans were recorded per mouse over the entire experimental period. A complete ethogram of mice's behaviours is shown in Table 1 .

\section{Data analyses}

Data was organized and summarized and tested for normality, linearity and homogeneity of variance. Then the average percentage of scans spent performing each behavioural pattern for each individual mouse was calculated by dividing the number of scans for each behavioural variable by the total number of scans and the resultant value was multiplied by 100 . Twoway ANOVA was used to test for differences in behavioural patterns between the two strains of mice (DBA/2 and C57BL/6J) within the two experimental treatments (group and single housing) and result were expressed as Means \pm standard error $(\mathrm{M} \pm \mathrm{SEM})$ as independent variables followed by Bonferroni-PostHoc tests to compare each strain to its housing type using SPSS V.20. In cases of the significant interactions (interaction between two variables), e.g. housing system*strain, general linear model was used to compare means of behavioural patterns with different housing system as a factor and strain as a dependent variable. 


\section{Results}

\section{Main effect of experimental treatment}

The output of the two-way ANOVA-test showed that there was an effect of housing conditions on the home cage behaviour of mice with the mice in the $\mathrm{SH}$ treatment displaying higher levels of enrichment-directed behaviours $\left(\mathrm{F}_{3,60}=27.59, \mathrm{P}=0.001\right)$ (Fig. 1) than those in the $\mathrm{GH}$, and those of C57BL/6J displayed higher levels of bedding-directed behaviours $\left(\mathrm{F}_{3,60}=5.647, \mathrm{P}=0.035\right)$ (Fig. 3) compared to their conspecifics in $\mathrm{GH}$ treatment. On the other hand, GH mice showed higher levels of ingestive behaviour compared to $\mathrm{SH}$ mice $\left(\mathrm{F}_{3,60}=10.851, \mathrm{P}=0.01\right)$ (Fig. 4).

\section{Main effect of strain}

Several behaviour patterns recorded in this study showed an effect of mouse strain: Enrich ment-directed behaviour and sleep were higher in $\mathrm{DBA} / 2 \mathrm{~J}$ mice in both housing conditions compared to $\mathrm{C} 57 \mathrm{BL} / 6 \mathrm{~J} \quad\left(\mathrm{~F}_{3,60}=30.654, \mathrm{P}=\right.$ 0.001) (Fig. 1) $\left(\mathrm{F}_{3,60}=44.075 .94, \mathrm{P}=0.001\right)$ (Fig. 5) respectively, in contrast, exploration $\left(\mathrm{F}_{3,60}=54.327, \mathrm{P}<0.001\right)$ (Fig. 6) and locomotion $\left(\mathrm{F}_{3,60}=37.623, \mathrm{P}<0.001\right)$ (Fig. 7) were higher in $\mathrm{C} 57 \mathrm{BL} / 6 \mathrm{~J}$.

\section{Housing *strain interaction effects}

$\mathrm{SH}$ mice of the DBA/2J strain displayed higher levels of grooming $\left(\mathrm{F}_{3,60}=9.204, \mathrm{P}=\right.$ 0.01) (Fig. 2). Whereas bedding-directed behaviours in $\mathrm{SH}$ treatment $\left(\mathrm{F}_{3,60}=9.661, \mathrm{P}<\right.$ 0.009) (Fig. 3) were more frequently performed by C57BL/6J mice than those of DBA/2J. Furthermore, feeding behaviour were highly significant in $\mathrm{GH}$ treatment in $\mathrm{DBA} / 2 \mathrm{~J}$ mice $\left(\mathrm{F}_{3,60}=11.083, \mathrm{P}=0.006\right)$ (Fig. 4).

Table 1: Ethogram for behavioural elements recorded

\begin{tabular}{|c|c|}
\hline Behavioural category & Description \\
\hline Feeding behaviour & Rears up to gnaw at food pellets through the bars of the food hopper. \\
\hline Grooming & Lick its fur, groom with the forepaws, or scratch with any limb. \\
\hline Sleep & $\begin{array}{l}\text { Lying un alert with both eyes closed, curled up on its side, with its face } \\
\text { tucked into its body and motionless. }\end{array}$ \\
\hline $\begin{array}{l}\text { Exploratory behaviour (investigation } \\
\text { of food and environment) }\end{array}$ & $\begin{array}{l}\text { Investigate food; investigate a non-food object in the environment } \\
\text { (Sniffing cage wall, cage top and cage floor, (air-in) sniffing air inside } \\
\text { the cage). }\end{array}$ \\
\hline Bedding-directed behaviours & $\begin{array}{l}\text { Digging, sniffing bedding, bedding manipulation (pushing bedding ma- } \\
\text { terial forwards or backwards with nose, forepaws or hind legs) and bur- } \\
\text { rowing. }\end{array}$ \\
\hline Locomotion & Movement in the cage. \\
\hline In-the-crawl ball & $\begin{array}{l}\text { Mice were encapsulated by the crawl ball in which the whole body of } \\
\text { the animal- with or without its tail- was inside the ball. }\end{array}$ \\
\hline
\end{tabular}




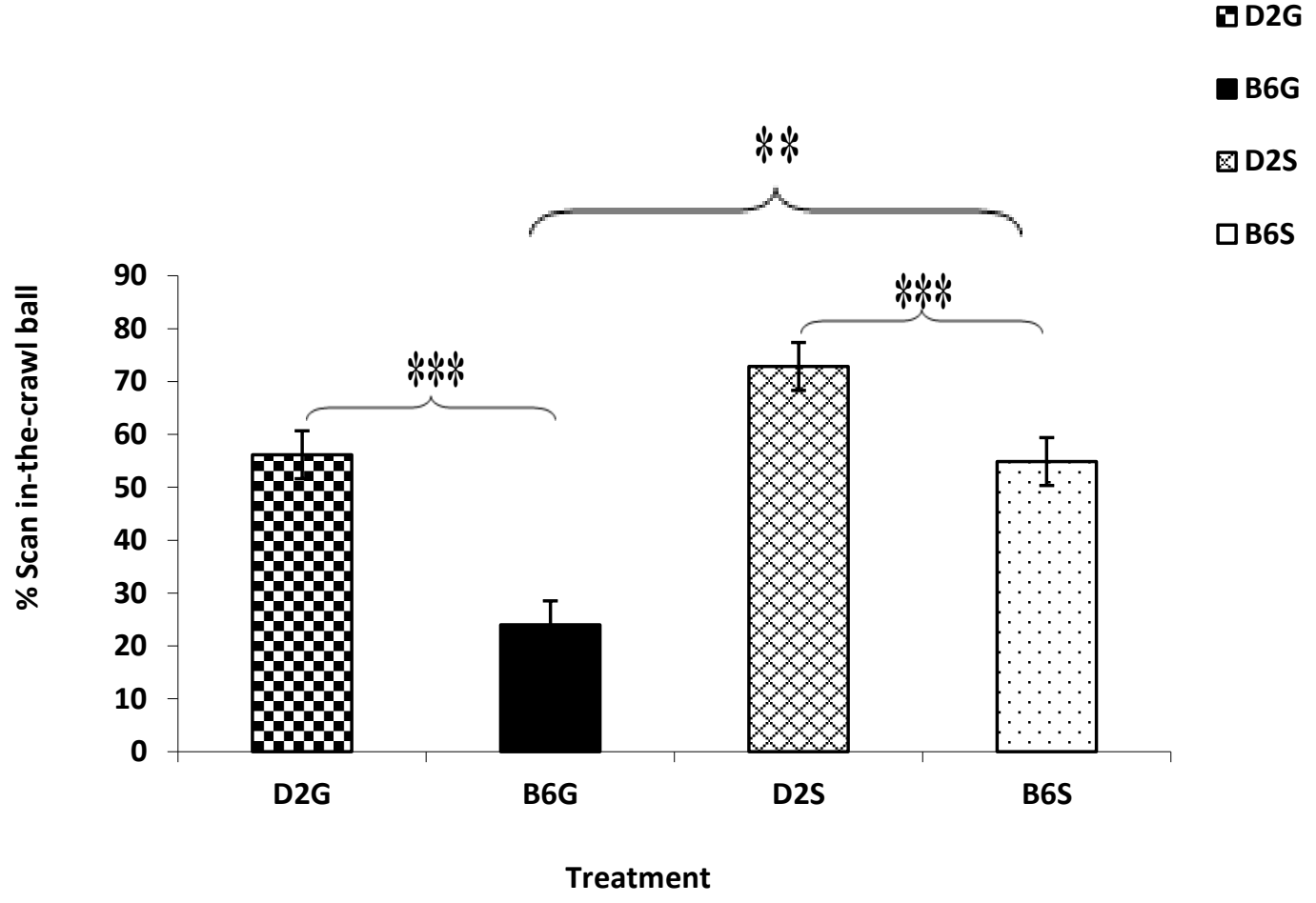

Figure 1: Average $\%$ of scans in the crawl-ball by the mice of the two inbred strains in the two experimental treatments. Data represent mean $\pm \mathrm{SEM}, * * * \mathrm{P}<0.001$, ** $\mathrm{P}<0.01$. D2G: GH-DBA/2; B6G: GH-C57BL/6J; D2S: SH-DBA/2; B6S: SH- C57BL/6J

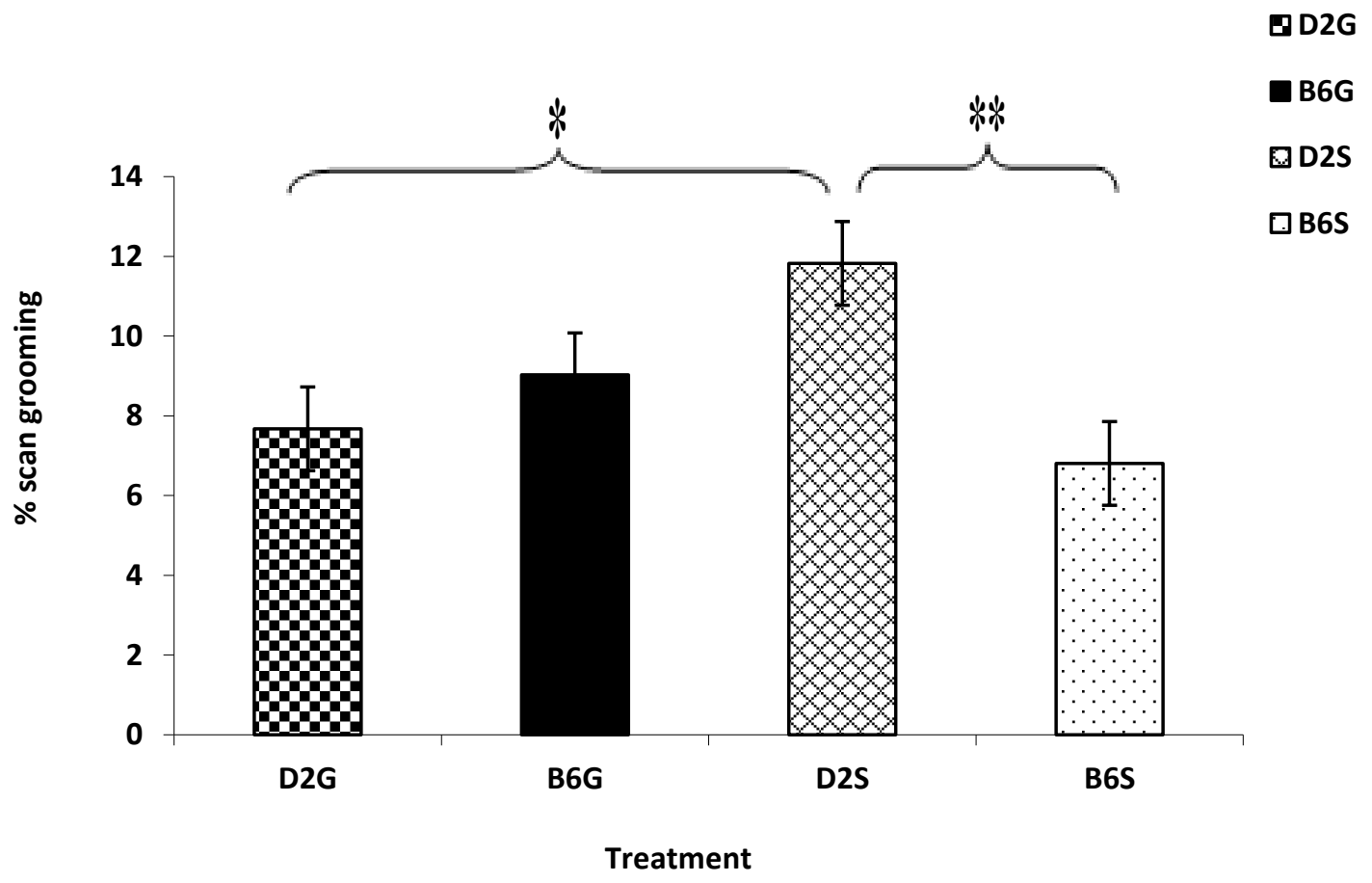

Figure 2: Average $\%$ of scans grooming by the mice of the two inbred strains in the two experimental treatments. Data represent mean $\pm \mathrm{SEM}, * * \mathrm{P}<0.01, * \mathrm{P}<0.05$. D2G: GH-DBA/2; B6G: GH-C57BL/6J; D2S: SH-DBA/2; B6S: SH- C57BL/6J 


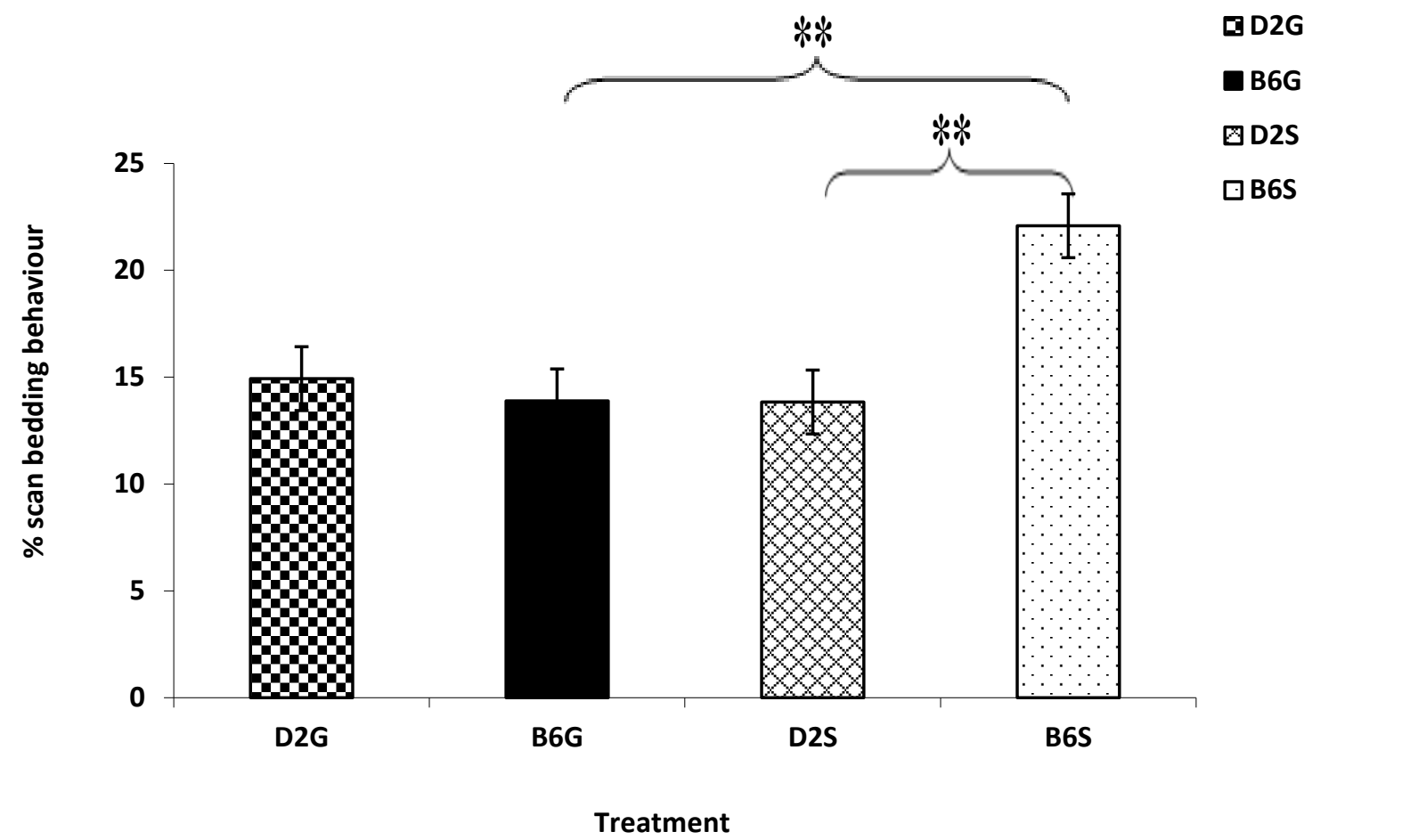

Figure 3: Average $\%$ of scans in bedding-directed behaviour by the mice of the two inbred strains in the two experimental treatments. Data represent mean $\pm \mathrm{SEM}$, ** $\mathrm{P}<0.01$. D2G: GH-DBA/2; B6G: GHC57BL/6J; D2S: SH-DBA/2; B6S: SH- C57BL/6J

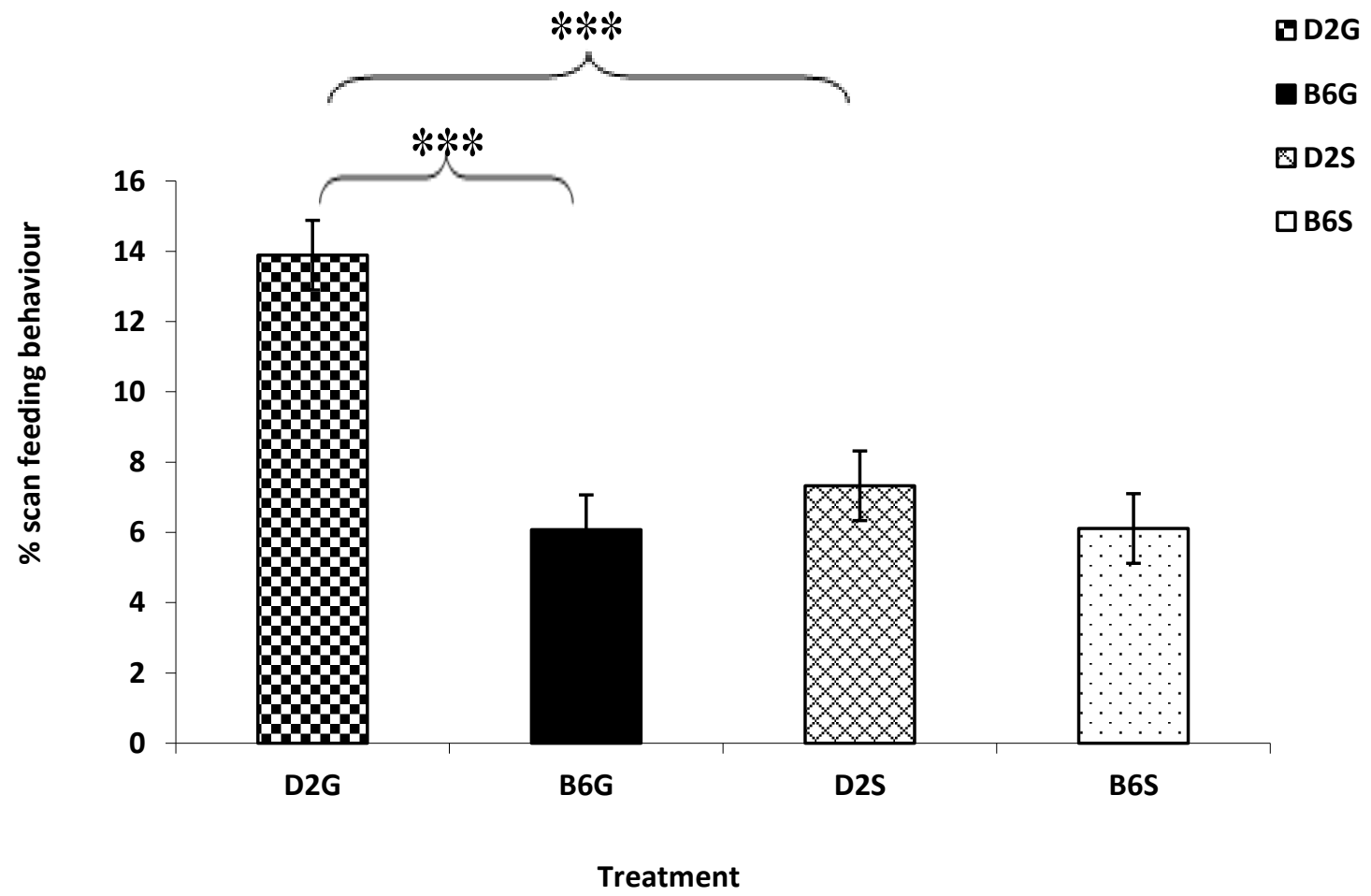

Figure 4: Average $\%$ of scans in feeding behaviour by the mice of the two inbred strains in the two experimental treatments. Data represent mean $\pm \mathrm{SEM}$, *** $\mathrm{P}<0.001$. D2G: GH-DBA/2; B6G: GH-C57BL/6J; D2S: SH-DBA/2; B6S: SH- C57BL/6J 


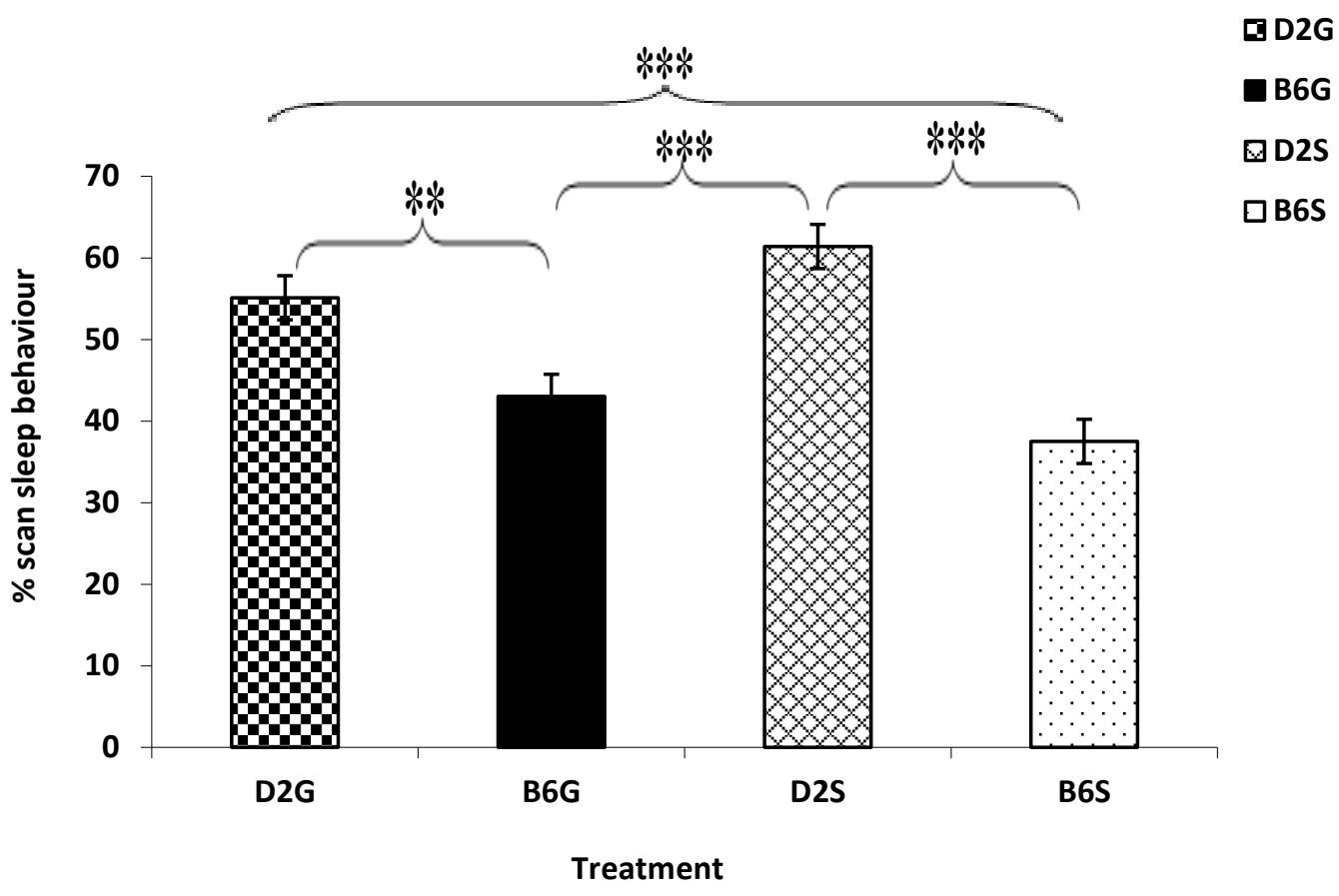

Figure 5: Average \% of scans sleeping by the mice of the two inbred strains in the two experimental treatments. Data represent mean $\pm \mathrm{SEM}, * * \mathrm{P}<0.01$, *** $\mathrm{P}<0.001$. D2G: GH- DBA/2; B6G: GH-C57BL/6J; D2S: SH-DBA/2; B6S: SH- C57BL/6J

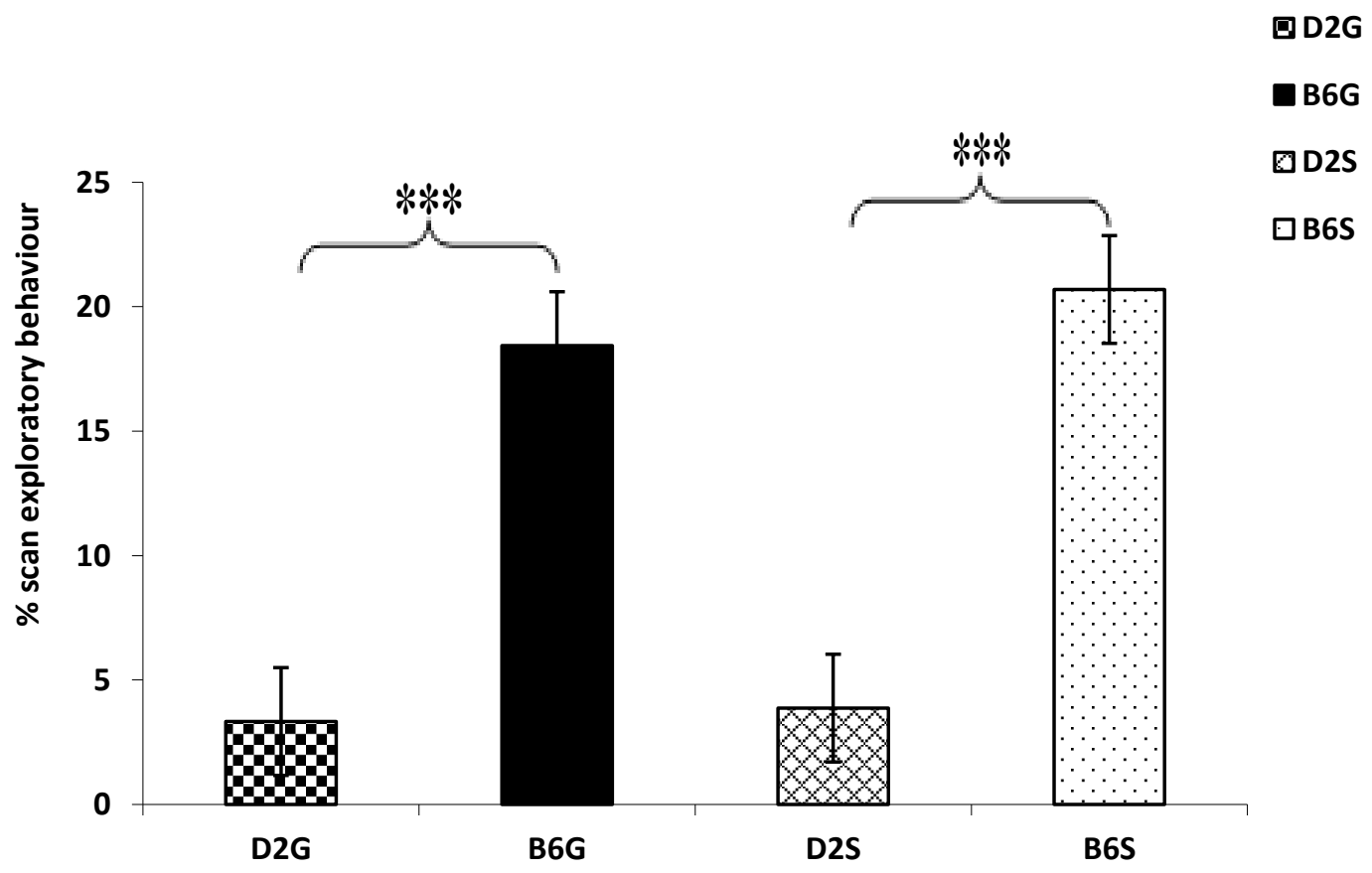

Treatment

Figure 6: Average \% of scans in exploratory behaviour by the mice of the two inbred strains in the two experimental treatments. Data represent mean $\pm \mathrm{SEM}$, *** $\mathrm{P}<0.001$. D2G: GH-DBA/2; B6G: GHC57BL/6J; D2S: SH-DBA/2; B6S: SH- C57BL/6J 


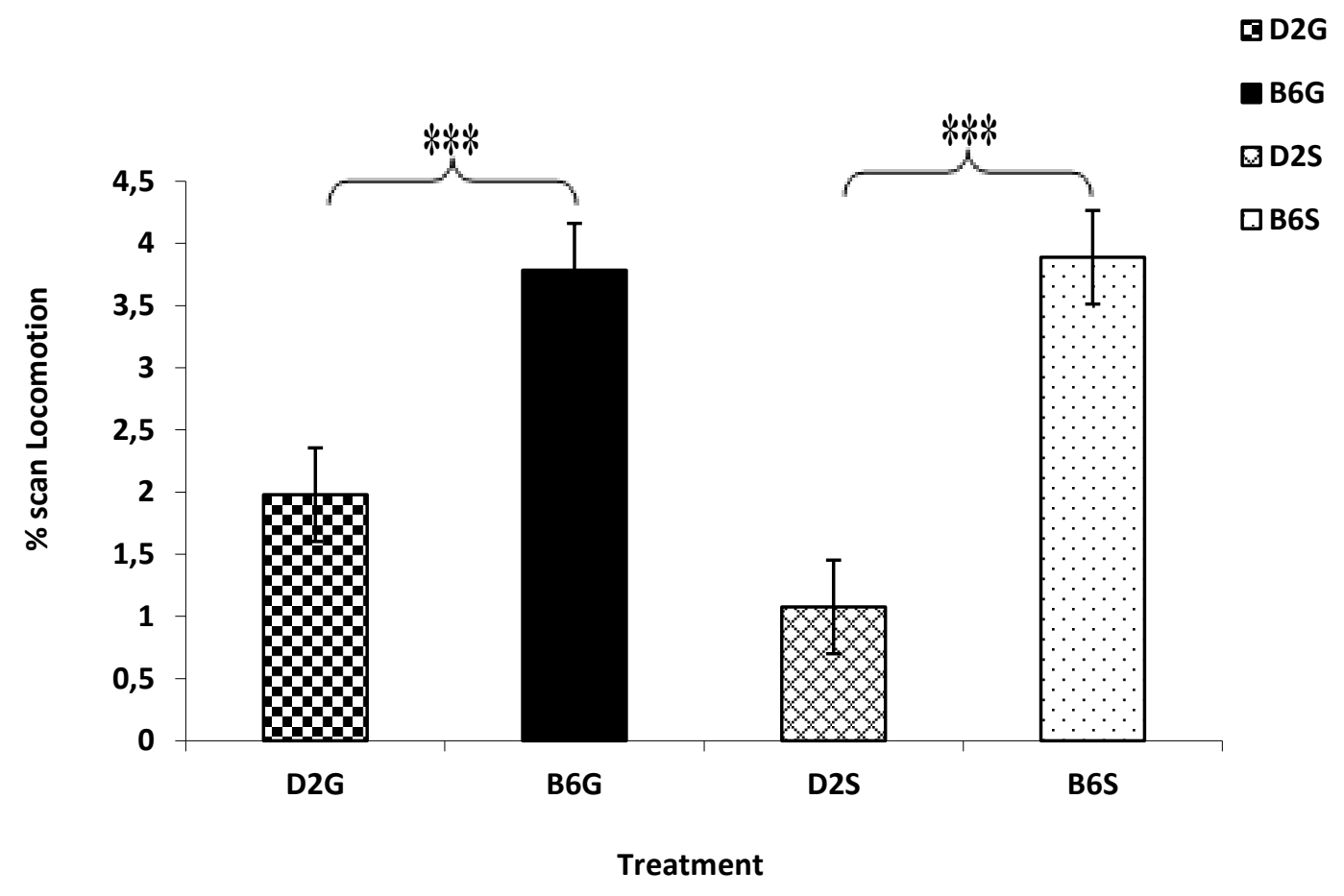

Figure 7: Average $\%$ of scans in locomotion by the mice of the two inbred strains in the two experimental treatments. Data represent mean $\pm \mathrm{SEM}, * * * \mathrm{P}<0.001$. D2G: GH- DBA/2; B6G: GH-C57BL/6J; D2S: SHDBA/2; B6S: SH- C57BL/6J

\section{Discussion}

The aim of this experiment was to examine whether home cage behaviours vary between laboratory mice experiencing different housing conditions between two of the commonly used strains of mice, namely DBA/2J and C57BL/6J. The results of this study show clear differences between mice in different social environments where SH increased the levels of some behaviours including presence in the crawl-ball, grooming and bedding-directed behaviour whereas GH enhanced other behaviours such as feeding behaviour. The strain of the mice also had a significant effect on their home cage behaviours with individuals of the DBA/2J strain were more frequently seen sleeping, feeding, grooming, and in-the-crawl ball, and less frequently explorative, locomotive and directing behaviours towards bedding materials compared to mice of the C57BL/6J strain.
Although home cage behaviours play an integral role in monitoring stress responses and anxiety, there have been remarkably few studies comparing these behaviours particularly between the C57BL/6J and DBA/2 strains of laboratory mice. There has been some confusion surrounding the differences in behaviour between the strains. Frequent observations in many behavioural tests such as the novelty-induced locomotor activity test demonstrated that C57BL/6 was a highly active strain and that the DBA/2 was an intermediate one (19). Likewise, other reports showed that C57BL/6 was significantly more active (20) than DBA/2 strain. Other studies, however, could not establish a significant difference in activity between the two strains (21), while some found that DBA/2 strain was significantly more active than the C57BL/6 strain (22).

The results presented here showed a strain difference in the time period of sleep behaviour, with individuals of the DBA/2J strain sleeping 
more than those of $\mathrm{C} 57 \mathrm{BL} / 6 \mathrm{~J}$ strain in both housing conditions ( $\mathrm{GH}$ and $\mathrm{SH})$. This result supports that of (23) who found that DBA/2J mice were more anxious than C57BL/6J. Previous studies showed that mice with elevated levels of anxiety slept more and showed longer sleep latencies than those with low levels of anxiety (24). Differences in the levels of exploratory behaviour reported between strains of mice in the current experiment can also be explained in the light of anxiety levels of the two strains. Lower levels of exploratory behaviour expressed by individuals of DBA/2J could be due to the fact that they are more anxious than C57BL/6J. It has been previously shown that exploratory behaviour is influenced by levels of anxiety in which high level of anxiety suppresses exploration, and anxiety is associated with behavioural transition from ongoing behaviours such as transition from exploration to flight (escape) or other defensive behaviours (25-27).

Studies have compared locomotor activities between these strains of mice; however, these studies often compared their performance in different locomotor tests and the conclusions were inconsistent. For instance, C57BL/6J was shown as a higher-activity mouse strain than DBA/2J (28) whereas; no significant activity difference between the two strains (21). It was also found that DBA/2J mice were more active than C57BL/6J (22). Our findings compared their performance in their original home cages and showed that $\mathrm{C} 57 \mathrm{BL} / 6 \mathrm{~J}$ mice performed more locomotor activity than DBA/2. Such results agree with those who illustrated that background strain differences and genetic mutations can affect locomotion (29). Furthermore, our results can fit with other findings which associated excessive motor activities with $\mathrm{C} 57 \mathrm{BL} / 6 \mathrm{~J}$ mice (19). These results indicate that there are significant differences in activity and exploration between strains of mice. Therefore, differences between inbred mice should be considered when interpreting results from studies using inbred mouse strains (30).

Our data also showed a strain effect and treatment effect for being in-the-crawl ball. $\mathrm{DBA} / 2 \mathrm{~J}$ mice were seen in the crawl ball more frequently than C57BL/6J and this can be explained in reference to their high level of anxiety. DBA/2 mice were more prone to hide inside the crawl ball due to their high level of anxiety and fear response. The crawl ball can encapsulate small rodents like mice therefore providing them with shelter and retreat. This is consistent with the performance of these strains in the elevated plus maze where DBA/2J was shown to spend more time in the closed arms of the maze than C57BL/6J (31). On the other hand, $\mathrm{SH}$ mice of the two strains were more frequently seen in-the-crawl ball compared to $\mathrm{GH}$ counterparts. This could be due to $\mathrm{SH}$ mice treated crawl ball as the only surrogate physical contact in their environment that can receive their attention at the expense of other behaviour, whereas $\mathrm{GH}$ mice directed much of their behaviour towards conspecific animals in the cage.

Our results also found greater feeding behaviour in $\mathrm{DBA} / 2 \mathrm{~J}$ mice compared to $\mathrm{C} 57 \mathrm{BL} / 6 \mathrm{~J}$ in $\mathrm{GH}$ mice. It was reported that food ingestion of individually housed male DBA/2J mice was greater than that of male C57BL/6J by $5-10 \%(32,33)$. Similarly, it was found that food intake of $\mathrm{DBA} / 2$ mice was $50 \%$ higher than in C57BL/6J (34). The same author did not explain the difference between their results in 2005 and 2007 but given that DBA/ 2 mice have higher basal metabolic rate by $30 \%$ and a core temperature $0.7^{\circ} \mathrm{C}$ higher than $\mathrm{C} 57 \mathrm{BL} / 6 \mathrm{~J}$ (35), small differences in ambient temperature could explain the strain difference.

The reason for high levels of feeding performed by DBA/2J mice in GH conditions compared to SH could be their high levels of energy expenditure and movement activity. $\mathrm{SH}$ $\mathrm{DBA} / 2 \mathrm{~J}$ mice were found to sleep more and to move less than their conspecifics in GH situation therefore consuming less food. It could also be due to high levels of social interaction (both aggressive and non-aggressive) in $\mathrm{GH}$ situation. On the other hand, low level of food intake in SH condition could be due to stress experienced by these animals. Chronic stress has been shown to have an anorexic affect (reduces food and water intake) (36) in laboratory rodents. 
There was also a strain-housing interaction effect on the level of grooming behaviour with DBA/2J self-groomed more than C57BL/6J in single housing situations. The higher level of grooming expressed by DBA/2J mice could be due to the high levels of sleep in these animals. Self-grooming was reported as the most timeconsuming activity of the laboratory rodent awake time and second most time-consuming activity in laboratory rodents after sleep and was reported to be concentrated around sleeping time. It takes place after sleeping, but also occurs when the animal prepares for sleep (37). But it could also be due to the high levels of anxiety in these animals $(38,39)$ as grooming could be acting as an alternative satisfier or "tension- reducer". Similarly, it was illustrated that grooming is extensively identified as a behavioural marker of stress in rodents (40), suggesting the possibility that more grooming in $\mathrm{DBA} / 2 \mathrm{~J}$ mice especially in single rather than group housed situation may be due to the high level of anxiety in this strain. The reason for the finding that $\mathrm{SH}$ mice groomed more than $\mathrm{GH}$ mice could be the stress of single housing. It has been illustrated that mice are social animals thus individual housing is a kind of stressful condition for them (41).

The results of the current experiment also revealed that $\mathrm{SH}$ mice of the $\mathrm{C} 57 \mathrm{BL} / 6 \mathrm{~J}$ strain exhibited higher levels of bedding-directed behaviours compared to those of the GH. The increase in the level of bedding-directed behaviour by the $\mathrm{SH}$ mice could be explained as an attempt to escape. Single housing of laboratory rodents in laboratory cages has been shown to be stressful and to increase specific forms of behaviours termed as 'escape-related' (42). Whereas the increased level of bedding-directed behaviours by the $\mathrm{C} 57 \mathrm{BL} / 6 \mathrm{~J}$ than DBA/2J mice could reflect their high level of activity and exploration.

\section{Conclusion}

Our findings clearly highlight the importance of social factors and strain in modulating the behaviour of inbred mice and call for cautious interpretations of behavioural changes incurred by these factors. Moreover, understanding strain differences in behaviours of
DBA/2J and C57BL/6J mice may help us in finding better animal models of specific neurobehavioural responses in terms of genotype-dependent sensitivity of animals to stress and its relation to their behaviours. For example, our data on higher locomotion in C57BL/6 J mice suggest that $\mathrm{C} 57 \mathrm{BL} / 6 \mathrm{~J}$ mice may be a better choice than DBA/2J in order to study the effects of genetic mutations and drug administration likely to affect such behaviour.

\section{Contributions}

Ahmed F. Abou-Elnaga and Ibrahim F. Rehan designed the survey protocol, supervised data collection procedures and drafted the final version of the manuscript; Ralph RJ Thompson, Usama A. Abou-Ismail, Motamed E. Mahmoud, Radi A. Mohamed and Hesham H, Mohammed analysed the data and shared in experimental protocol; Ahmed A. Sabek and Mohamed Z. Elhussiny have finalized the experimental design and revised the manuscript. All authors contributed to, editing, and approving the final manuscript as submitted.

\section{Competing financial interests}

The authors declare that they have no competing financial interests and non-financial interests.

\section{Acknowledgments}

We thank the staff at the Department of Husbandry and Development of Animal Wealth, Faculty of Veterinary Medicine, Mansoura University, Egypt for providing materials used in this study.

\section{References}

1. Balcombe JP. Laboratory environments and rodents' behavioural needs: a review. Laboratory Animals 2006; 40(3): 217-235.

2. Hueihan J, Estibaliz G, Xinlin Y, Vinita K, Tomaso P, Andrew, DS, Thomas S. Automated home-cage behavioural phenotyping of mice. Nature Communications 2010; 1(5): 1-9.

3. Crawley J. What's wrong with my mouse? Behavioral phenotyping of transgenic and knockout mice. $2^{\text {nd }}$ Ed. John Wiley \& Sons 2007.

4. Jung YH, Hong SI, Ma SX, Hwang JY, Kim JS, Lee JH, Seo JY, Lee SY, Choon-Gon JG. Strain differences in the chronic mild stress animal model 
of depression and anxiety in mice. Biomolecular Research and Therapeutics 2014; 22(5): 453-9.

5. Thomsen MS, Caine SB. 2011. Psychomotor stimulant effects of cocaine in rats and 15 mouse strains. Experimental and Clinical Psychopharmacology 2011; 19(5): 321-41.

6. Hiyoshi H, Terao A, Ogura YO, Kimura K. Characteristics of sleep and wakefulness in wild-derived inbred mice. Experimental Animals 2014; 63(2): 205-13.

7. Chen Q, Panksepp JB, Lahvis GP. Empathy is moderated by genetic background in mice. PLoS One 2009; 4(2): 4387.

8. Wahlsten D, Rustay N, Metten P, Crabbe J. In search of a better mouse test. Trends in Neurosciences 2003; 26: 132-6.

9. Bains RS, Cater HL, Sillito RR, Chartsias A, Sneddon D, Concas D, Bond P, Lukins TC, Wells S, Arozena AA, Nolan PM, Armstrong JD. Analysis of individual mouse activity in group housed animals of different inbred strains using a novel automated home cage analysis system. Frontier in Behavioral Neuroscience 2016; 10: 106.

10. Villani C, Sacchetti G, Bagnati R, Passoni A, Fusco F, Mirjana CM, Invernizzi WR. Lovastatin fails to improve motor performance and survival in methyl-CpG-binding protein 2-null mice. eLife 2016; 5: 22409.

11. Cabib S, Orsini C, Le Moal M, Piazza PV. Abolition and reversal of strain differences in behavioral responses to drugs of abuse after a brief experience. Science 2000; 289(5478): 463-5.

12. Kas MJH, Van RJM. Dissecting complex behaviours in the post-genomic era. Trends in Neurosciences 2004; 27(7): 366-369.

13. Kamakura R, Kovalainen M, Leppäluoto J, Herzig KH, Mäkelä KA. The effects of group and single housing and automated animal monitoring on urinary corticosterone levels in male C57BL/6 mice. Physiological Reports 2016; 4(3): 12703

14. Hunt C, Hambly C. Faecal corticosterone concentrations indicate that separately housed male mice are not more stressed than group housed males. Physiology \& Behavior 2006; 87(3): 51926.

15. Bartolomucci A, Palanza P, Sacerdote P, Ceresini G, Chirieleison A, Panerai AE. Individual housing induces altered immune-endocrine responses to psychological stress in male mice. Psychoneuroendocrinology 2003; 28(4): 540-58.

16. Arndt SS, Laarakker MC, vanLith HA, van der Staay FJ, Gieling E, Salomons AR. Individual housing of mice-impact on behaviour and stress responses. Physiology \& Behavior 2009; 97(3-4): 385-93.

17. Olsson AS, Westlund K. More than numbers matter: the effect of social factors on behaviour and welfare of laboratory rodents and nonhuman primates. Applied Animal Behaviour Science 2007; 103(3): 229-54.

18. Abou-Ismail UA, Mahboub HD. The effects of enriching laboratory cages using various physical structures on multiple measures of welfare in singly-housed rats. Laboratory Animals 2011; 45(3): 145-53.

19. Cabib S, Puglisi-Allegra S, Ventura R. The contribution of comparative studies in inbred strains of mice to the understanding of the hyperactive phenotype. Behavioural Brain Research 2002; 130(12): 103-9.

20. Hatcher JP, Jones DN, Rogers DC, Hetcher PD, Reavill C, Hagan JJ, Hunter AJ. Development of SHIRPA to characterize the phenotype of genetargeted mice. Behavioural Brain Research 2001; 125(1-2): 43-7.

21. Bolivar VJ, Caldarone BJ, Reilly AA, Flaherty L. Habituation in theopen field: asurvey of inbred strains and F1 hybrids. Behavior Genetics 2000; 30(4): 258-93.

22. Rogers DC, Jones DN, Nelson PR, Jones CM, Quilter CA, Robinson TL, Hagan JJ. Use of SHIRPA and discriminant analysis to characterize marked differences in the behavioural phenotype of six inbred mouse strains. Behavioural Brain Research 1999; 105(2): 207-17.

23. Brigman JL, Mathur PL, Williams RW, Holmes A. Genetic relationship between anxiety-related and fear-related behaviors in BXD recombinant inbred mice. Behavioural Pharmacology 2009; 20(2): 204-9.

24. Vladimira J, Cornelia F, Rainer L, Mayumi $\mathrm{K}$. Sleep phenotyping in a mouse model of extreme trait anxiety. PLoS One 2012; 7(7): 40625.

25. Campos AC, Fogaga MV, Aguiar DC, Guimaraes FS. Animal models of anxiety disorders and stress. Revista Brasileira Psiquiatria 2013; 35(2): 101-11.

26. Fraser ML, Brown RE, Hussin A, Fontana M, Whittaker A, Timothy PO, Lederle L, Holmes A, Ramos A. Measuring anxiety- and locomotionrelated behaviours in mice: a new way of using old tests. Psychopharmacology 2010; 211(1): 99-112.

27. Steimer T. Animal models of anxiety disorders in rats and mice: some conceptual issues Dialogues. Journal of Clinical Neuroscience 2011; 13(4): 495-506. 
28. Cabib $\mathrm{S}$. The contribution of studies in inbred strains of mice to understanding of a hyperactive phenotype. Behavioural Brain Research 2002; 130(1-2): 103-9.

29. Bailey KR, Crawley JN. Anxiety-related behaviors in mice. In methods of behavior analysis in neuroscience $2^{\text {nd }}$ ed. Boca Raton (FL). CRC Press/Taylor \& Francis 2009.

30. Wood E. A behavioral comparison of four inbred strains of mice. Ph.D. Thesis. Virginia, Virginia Commonwealth University, USA 2010.

31. Võikar V, Polus A, Vasar E, Rauvala H. Long-term individual housing in C57BL/6J and DBA/2 mice: assessment of behavioral consequences. Genes, Brain and Behavior 2005; 4(4): 240-52.

32. Bachmanov AA, Reed DR, Beauchamp GK, Tordoff MG. Food intake, water intake and drinking spout side preference of 28 mouse strains. Behavior Genetics 2002; 32(6): 435-43.

33. Lewis SR, Ahmed S, Dym C, Khaimova E, Kest B, Bodnar RJ. Inbred mouse strain survey of sucrose intake. Physiology \& Behavior 2005; 85(5): 546-56.

34. Lewis SR, Dym C, Chai C, Singh A, Kest B, Bodnar RJ. Genetic variance contributes to ingestive processes: A survey of eleven inbred mouse strains for fat (Intralipid) intake. Physiology \& Behavior 2007; 90(1): 82-94.

35. Ferguson, M, Rebrin I, Forster MJ, Sohal RS. Comparison of metabolic rate and oxidative stress between two different strains of mice with varying response to caloric restriction. Experimental Gerontology 2008; 43(1): 757-63.

36. Vallès A, Martí O, García A, Armario A. Single exposure to stressors causes long-lasting, stressdependent reduction of food intake in rats. American Journal of Physiology; Regulatory Integrative Comparative Physiology 2000; 279(3): 1138-44.

37. Saibaba P, Sales GD, Stodulski G, Hau J. Behaviour of rats in their home cages: daytime variation and effects of routine husbandry procedures analysed by time sampling techniques. Laboratory Animals 1996; 30(1): 13-21.

38. D'Aquila PS, Peana AT, Carboni V, Serra G. Exploratory behaviour and grooming after repeated restraint and chronic mild stress: effect of desipramine. European Journal of Pharmacology 2000; 399(1): 43-7.

39. Kantor S, Anheuer ZE, Bagdy G. High social anxiety and low aggression in Fawn-Hooded rats. Physiology \& Behavior 2000; 71(5): 551-7.

40. Kalueff AV, Tuohimaa P. Contrasting grooming phenotypes in C57B1/6 and 129S1/SvImJ mice. Brain Research 2004; 1028(1): 75-82.

41. Van Loo PL, Van Zutphen LF, Baumans V. Male management: coping with aggression problems in male laboratory mice. Lab Animal 2003; 37(4): 300-13.

42. Hurst JL, Barnard CJ, Tolladay U, Nevison $\mathrm{CM}$, West CD. Housing and welfare in laboratory rats: effects of cage stocking density and behavioural predictors of welfare. Animal Behaviour 1999; 58(3): 563-86. 